\title{
Electronic Structure and Conformational Properties of Azines. Part 3. $\$$ Molecular Structure and Conformation of Tetramethoxyformaldazine: a Spectroscopic, X-Ray Crystallographic and MNDO Study
}

\author{
Günter Korber, ${ }^{a}$ Paul Rademacher ${ }^{a \star}$ and Roland Boese ${ }^{b}$
}

anstitute of Organic Chemistry and ' Institute of Inorganic Chemistry, University of Essen, Universitätsstr. 5, D-4300 Essen, W. Germany

\begin{abstract}
Korber, G., Rademacher, P. and Boese, R., 1988. Electronic Structure and Conformational Properties of Azines. Part 3. Molecular Structure and Conformation of Tetramethoxyformaldazine: a Spectroscopic, X-Ray Crystallographic and MNDO Study. - Acta Chem. Scand., Ser. A 42: 571-577.

The electronic structure of tetramethoxyformaldazine (1) has been investigated by photoelectron spectroscopy and MNDO calculations. Some conformational properties and the molecular structure were analyzed by vibrational spectroscopy, MNDO calculations and X-ray crystallography. 1 is planar and centrosymmetric (molecular symmetry $C_{2 \mathrm{~h}}$ ). Correlations between electronic structure and conformational properties of azines with different substituents are discussed on the basis of a qualitative stereoelectronic model.
\end{abstract}

Dedicated to Professor Otto Bastiansen on his 70th birthday

In the course of our studies on the conformational properties of 2,3-diaza-1,3-dienes ${ }^{1,2}$ we have devised a qualitative stereoelectronic model to predict the relative stabilities of syn- (sc) or anticlinal (ac) and antiperiplanar (ap) conformations of azines with respect to their substituents. Since interactions between the $n, \pi$ and $\pi^{*}$ MO's are of prominent importance for the relative stabilities of the planar ap and the non-planar sc or ac conformations, the effect of substituents on the energies of these orbitals has to be examined. Substituents which raise the energy of the lonepair MO $n_{\mathrm{N}}{ }^{+}$and stabilize the LUMO $\pi^{*}$ or leave it unchanged, favour the interaction of these orbitals and therefore stabilize the twisted conformation. In a previous paper ${ }^{2}$ we have shown the acetyl groups in diacetyl monoazine (2) to cause this effect. On the other hand, substituents with a destabilizing effect on the $\pi$ MO's, which stabilize the $n$ MO's or leave them unaffected, will

\footnotetext{
${ }^{\S}$ Part 2, see Ref. 2.

*To whom correspondence should be addressed.
}

favour the planar ap conformation. Compounds such as alkylazines and amidazines have been shown to be planar. ${ }^{1,3}$ Thus, we claim that the cited electronic substituent effects determine the conformational behaviour to a large extent.

\section{Electronic structure of tetramethoxyformaldazine}

In order to further verify the conformational model, we have investigated the molecular structure and conformation of tetramethoxyformaldazine (1). Because of the presence of the oxygen lone-pair electrons, the electronic structure of azine 1 is much more complicated than that of the unsubstituted parent compound (3) or of simple alkyl derivatives. ${ }^{1}$ For the ap conformation of $\mathbf{1}$, point-group $C_{2 \mathrm{~h}}$, the two nitrogen lone-pair orbitals combine to form $n_{\mathrm{N}}{ }^{+}\left(a_{\mathrm{g}}\right)$ and $n_{\mathrm{N}}{ }^{-}\left(b_{\mathrm{u}}\right)$, while the two $\pi(C=N)$ orbitals yield the combinations $\pi^{+}\left(a_{\mathrm{u}}\right)$ and $\pi^{-}\left(b_{\mathrm{g}}\right)$. The four $n_{\pi}(\mathrm{O})$ orbitals form two combinations of $a_{\mathrm{u}}$ and two combinations of $b_{\mathrm{g}}$ symmetry, while the four $n_{\mathrm{o}}(\mathrm{O})$ orbitals yield 
KORBER ET AL.

$\mathrm{RR}^{\prime} \mathrm{C}=\mathrm{N}^{\mathrm{N}=\mathrm{CRR}^{\prime}}$

$\begin{array}{lllllllll}\mathrm{R}: & \mathrm{OCH}_{3} & \mathrm{CH}_{3} & \mathrm{H} & \mathrm{SCH}_{3} & \mathrm{H} & \mathrm{Br} & \mathrm{H} & \mathrm{CH}_{3} \\ \mathrm{R}^{\prime}: & \mathrm{OCH}_{3} & \mathrm{COCH}_{3} & \mathrm{H} & \mathrm{SCH}_{3} & \mathrm{CH}_{3} & \mathrm{Br} & \mathrm{C}_{6} \mathrm{H}_{5} & \mathrm{C}_{6} \mathrm{H}_{5}-\mathrm{CH}=\mathrm{CH} \\ \mathbf{1} & \mathbf{2} & \mathbf{3} & \mathbf{4} & \mathbf{5} & \mathbf{6} & \mathbf{7} & \mathbf{8}\end{array}$

two combinations of $a_{\mathrm{g}}$ and two combinations of $b_{\mathrm{u}}$ symmetry. Because of their symmetry, $n_{\mathrm{N}}{ }^{+}$and $n_{\mathrm{N}}{ }^{-}$, as well as $\pi^{+}$and $\pi^{-}$, can interact with two combinations of $n(\mathrm{O})$ MO's. This leads to six occupied $\pi$-type MO's (three of $a_{\mathrm{u}}$ and three of $b_{\mathrm{g}}$ symmetry) and six occupied $n$-type MO's (three of $a_{\mathrm{g}}$ and three of $b_{\mathrm{u}}$ symmetry). In order to obtain more quantitative information on the orbital energies we have performed $\mathrm{MNDO}^{4}$ calcula- tions for the planar ap conformation of 1. A correlation diagram for the calculated $n$ and $\pi$ MO's of 1, 3 and methanol is shown in Fig. 1.

Direct experimental access to electronic structure is possible by means of photoelectron (PE) spectroscopy. ${ }^{5}$ We have recorded the PE spectrum of 1 , which is reproduced in Fig. 2 . In the low energy part of the spectrum $(<12 \mathrm{eV})$ only two ionization bands occur, which both undoubt-

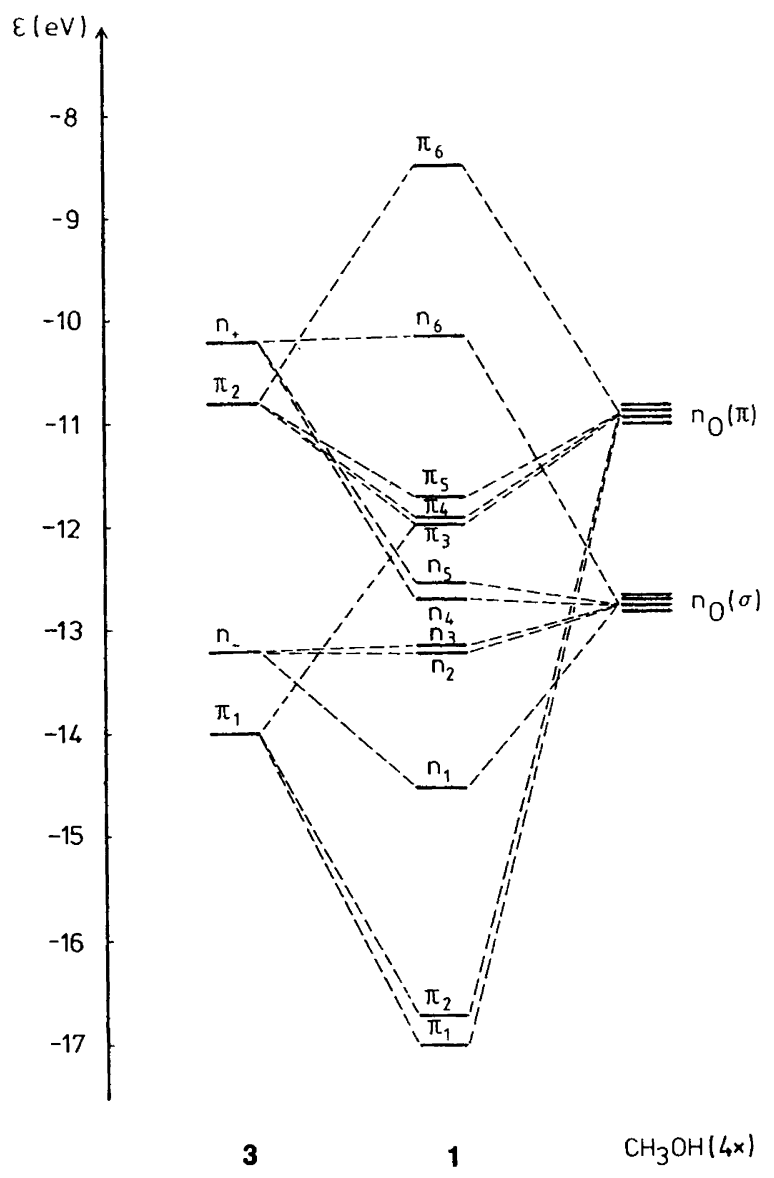

Fig. 1. Correlation diagram for the $n$ and $\pi$ MO's of 1,3 and $\mathrm{CH}_{3} \mathrm{OH}$. 


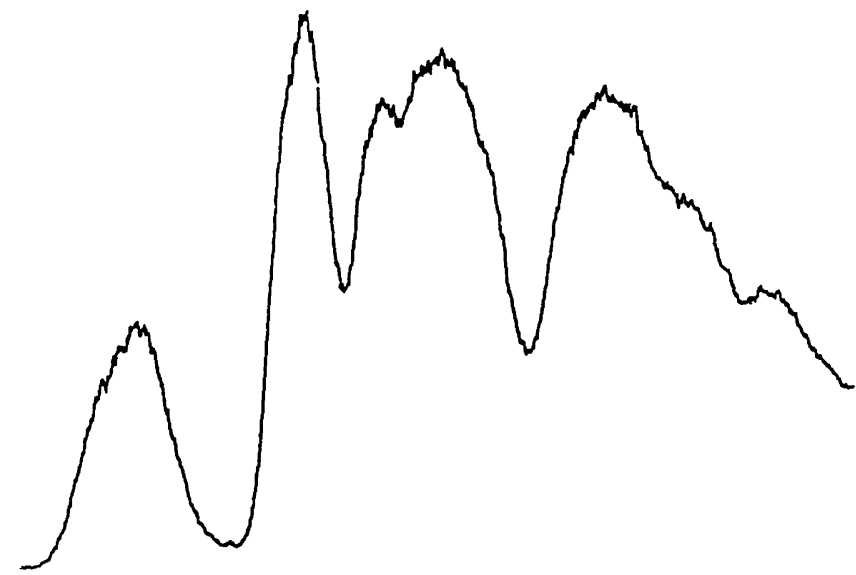

Fig. 2. PE spectrum of 1.

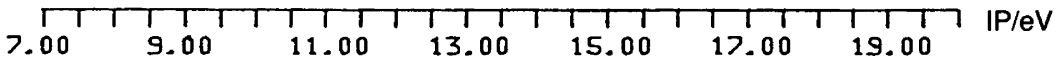

edly originate from several ionization events. Some of them are discernible as shoulders. In Table 1 the ionization potentials are summarized together with assignments to molecular orbitals, which are based on the MNDO results (Fig. 1).

As is obvious from Figs. 1 and 2, correspondence between ionization potentials and calculated orbital energies, as suggested by the Koopmans theorem, ${ }^{6}$ is rather unsatisfactory. However, taking into consideration the fact that energies of $\pi$ MO's of multiple bonds are calculated quite accurately by the MNDO method, while the corresponding computed values for $n_{\mathrm{N}}$ MO's are too low by ca. $1 \mathrm{eV},{ }^{4}$ the interpretation of the lowenergy part of the PE spectrum is possible without difficulty: The first, unusually broad band is a superposition of the ionizations of electrons from the MO's $\pi_{6}$ and $n_{6}$ (Fig. 1) which can be approximated as $\pi_{\mathrm{C}=\mathrm{N}}{ }^{-}\left(b_{\mathrm{g}}\right)$ and $n_{\mathrm{N}}{ }^{+}\left(a_{\mathrm{g}}\right)$, respectively.

Table 1. Vertical ionization potentials $\mathrm{IP}_{\mathrm{v}}(\mathrm{eV})$ of azine 1.

\begin{tabular}{|c|c|}
\hline $\mathbb{I P}_{\mathrm{v}}$ & Assignment \\
\hline $8.0 \mathrm{sh}$ & $\pi_{\mathrm{C}=\mathrm{N}}^{+} \quad\left(\pi_{6}\right)$ \\
\hline 8.55 & $n_{N}^{+} \quad\left(n_{6}\right)$ \\
\hline 10.85 & $n_{\pi}(\mathrm{O}) \quad\left(\pi_{3}-\pi_{5}\right)$ \\
\hline 12.03 & $n, \sigma$ \\
\hline 12.77 & $n, \sigma$ \\
\hline
\end{tabular}

The second, very intense band originates from ionizations of electrons from the MO's $\pi_{3}-\pi_{5}$, which roughly can be described as $n_{\pi}(\mathrm{O})$ MO's. In contrast to 3 and other aliphatic aldazines and ketazines, ${ }^{1}$ the HOMO of $\mathbf{1}$ is a $\pi$-type and not a $n$-type MO. MNDO calculations for other conformations did not lead to better correlations of orbital energies and ionization potentials. In summary, it can be stated that the PE spectrum of 1 is consistent with an ap-conformation.

\section{Infrared and Raman spectra}

Some conformational properties of 1 have been studied by vibrational spectroscopy. In order to find out whether all states of aggregation share the same conformation, we have measured infrared spectra of 1 as a solid in $\mathrm{KBr}$ and nujol, as well as in diluted solutions $\left(\mathrm{CCl}_{4}\right.$ and $\left.\mathrm{CS}_{2}\right)$. The frequencies of the strongest bands are given in the Experimental part.

The solution spectra exhibit sharp and wellresolved bands indicating 1 to be fixed in a definite conformation. The frequencies of the $v_{\mathrm{C}=\mathrm{N}}$ absorption reveal a profound polarity effect of $\mathrm{KBr}$ on the molecule. For both solutions the $\mathrm{C}=\mathrm{N}$ stretching vibration occurs at $1649 \mathrm{~cm}^{-1}$, while the value in $\mathrm{KBr}$ is $1630 \mathrm{~cm}^{-1}$. Furthermore, nearly all other bands are broadened, but not shifted, in the $\mathrm{KBr}$ matrix. In nujol, $v_{\mathrm{C}=\mathrm{N}}$ is found at $1648 \mathrm{~cm}^{-1}$, which is almost identical 
KORBER ET AL.

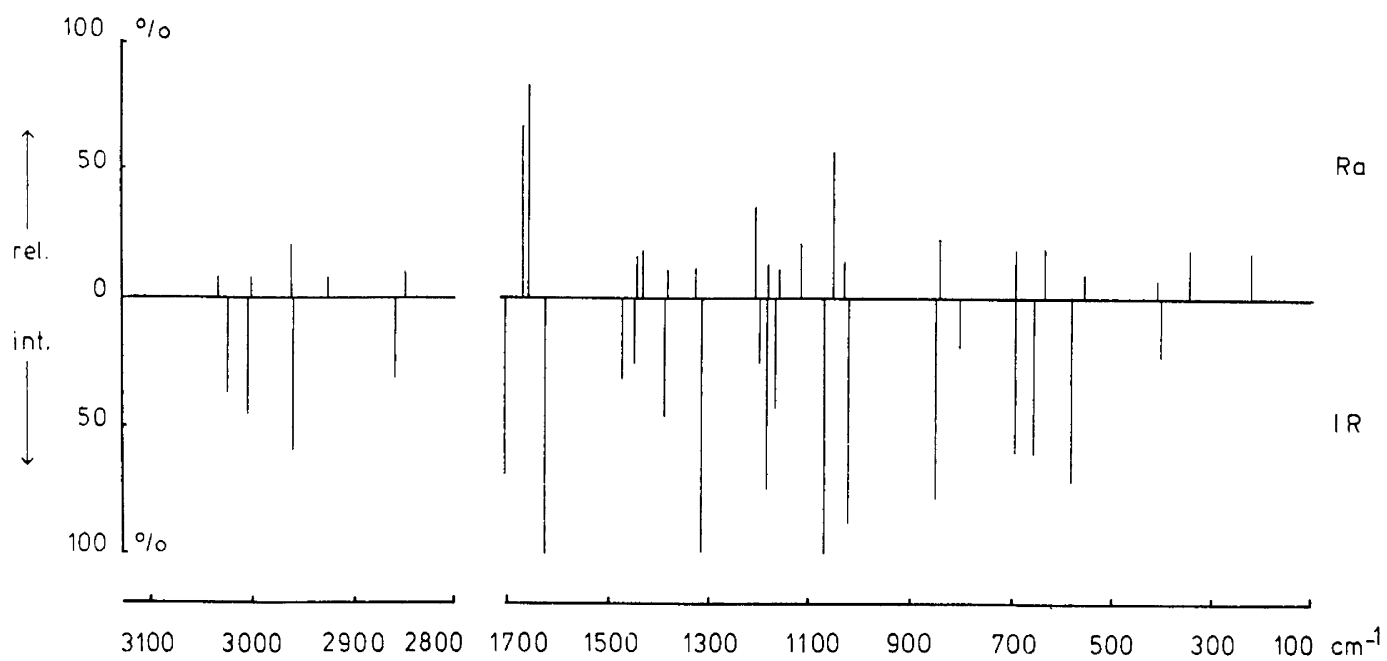

Fig. 3. IR and Raman bands of 1.

with the corresponding values observed in solutions. Since no bands appear or disappear on changing the state of aggregation, conformational changes are unlikely to occur.

In Fig. 3 the frequencies of IR and Raman bands for 1 as a solid are drawn for comparison. As the data reveal, nearly all frequencies are different in the IR and the Raman spectrum. This lack of coincidences of IR and Raman bands is strongly indicative of a centrosymmetric structure for 1 . Therefore, an ap-conformation for 1 is very probable.

\section{X-Ray structure analysis}

The conclusion reached on the basis of vibrational spectroscopy is confirmed by the X-ray analysis: Tetramethoxyformaldazine (1) is a molecule with very nearly $C_{2 \mathrm{~h}}$ symmetry. All nonhydrogen atoms are coplanar [maximum displacement from the mean-square plane: $3.7 \mathrm{pm}$ for atom $\mathrm{O}(1)$ ]. In Fig. 4 the experimental structure of 1 is shown.

The atomic coordinates of $\mathbf{1}$ are given in Table 2 . Bond lengths and bond angles are listed in Table 3 together with the results of a $\mathrm{MNDO}^{4}$ calculation. The numbering of atoms corresponds to that shown in Fig. 4.

As the bond lengths indicate, there are localized $\mathrm{C}=\mathrm{N}$ and $\mathrm{N}-\mathrm{N}$ bonds in 1 , their distances having values close to those expected ${ }^{7}$ for a $\mathrm{CN}$ double (theor. $129 \mathrm{pm}$ ) and a NN single bond (theor. $141 \mathrm{pm}$ ), respectively, all atoms being $s p^{2}$ hybridized. The $\mathrm{C}(1)-\mathrm{O}(1)$ and $\mathrm{C}(1)-\mathrm{O}(2)$ distances are not significantly different and correspond to $\mathrm{C}\left(s p^{2}\right)-\mathrm{O}$ single bonds (theor. $135 \mathrm{pm}$ ). Also, the $\mathrm{O}(1)-\mathrm{C}(2)$ and $\mathrm{O}(2)-\mathrm{C}(3)$ distances come close to the expected value $(143 \mathrm{pm})$ for a $\mathrm{C}\left(s p^{3}\right)-\mathrm{O}$ bond length. It is noteworthy that the molecule is planar even though the degree of $\pi$ electron delocalization is quite low. Packing of the molecules in the crystal is determined by van der Waals interactions. ${ }^{*}$

In order to explain the steric and electronic effects operating in 1 , the $\mathrm{C}=\mathrm{N}-\mathrm{N}=\mathrm{C}$ unit was kept planar in the MNDO calculation, while all other structure parameters were optimized. Comparison between the experimental and calculated data reveals important differences concerning bond lengths and angles as well as torsional angles. The calculated $\mathrm{N}-\mathrm{N}$ bond length is too short by $7.7 \mathrm{pm}$, while the value for the $\mathrm{C}=\mathrm{N}$ bonds is $5.8 \mathrm{pm}$ too large. Other examples of deviations relate to bond angles $[\mathrm{C}(2)-\mathrm{O}(1)-\mathrm{C}$

\footnotetext{
*A search for acyclic azines in the Cambridge Crystallographic Data File (version January 1987) revealed 32 entries, including compounds 4, 7 and 8. Only four compounds have ac conformations, all others being ap forms. Mean values of bond lengths: $\mathrm{N}-\mathrm{N} 140.5(1.8)$, $\mathrm{C}=\mathrm{N}$ 127.7(2.4) pm; bond angle: NNC 113.1(2.2).
} 


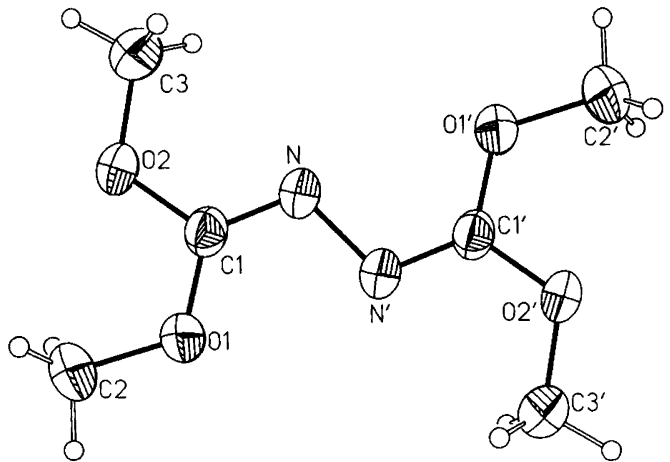

Fig. 4. X-Ray structure of 1 with thermal ellipsoids at the $50 \%$ probability level.

(1), $\mathrm{C}(3)-\mathrm{O}(2)-\mathrm{C}(1)]$ and torsion angles $[\mathrm{C}(2)$ $-\mathrm{O}(1)-\mathrm{C}(1)-\mathrm{N}, \mathrm{C}(2)-\mathrm{O}(1)-\mathrm{C}(1)-\mathrm{O}(2)]$.

These discrepancies are attributed mainly to interactions of the vicinal electron lone pairs located on the nitrogen atoms with each other and with neighbouring atoms in 1 . The MNDO method obviously does not provide a proper treatment of these contributions to molecular structure. For instance, it emphasizes conjugation of the two $\mathrm{C}=\mathrm{N}$ bonds in a planar conformation, and as a consequence atoms $\mathrm{C}(2)$ and $\mathrm{C}(3)$ are moved slightly out of the molecular plane for steric reasons. This is also valid for the abovementioned deviations concerning valence and torsion angles.

\section{Discussion}

Previous investigations ${ }^{1,2}$ prompted us to state that in going from the anti to a gauche conformation (sc or ac), the $\mathrm{N}-\mathrm{N}$ bond of the azine unit becomes shorter on account of increased $n / \pi^{*}$

Table 2. Atomic coordinates $\left(\times 10^{4}\right)$ for 1 (e.s.d.'s in parentheses).

\begin{tabular}{lrrl}
\hline & $x$ & $y$ & $z$ \\
\hline $\mathrm{N}$ & $732(2)$ & $113(3)$ & $4602(2)$ \\
$\mathrm{C}(1)$ & $1748(3)$ & $1749(3)$ & $4905(2)$ \\
$\mathrm{O}(1)$ & $1515(2)$ & $3136(2)$ & $5888(1)$ \\
$\mathrm{C}(2)$ & $2695(4)$ & $5002(4)$ & $6092(3)$ \\
$\mathrm{O}(2)$ & $3200(2)$ & $2269(2)$ & $4267(1)$ \\
$\mathrm{C}(3)$ & $3565(4)$ & $831(4)$ & $3212(3)$ \\
\hline
\end{tabular}

interactions and decreased steric repulsion effects of the nitrogen lone pairs. The observation of a relatively long $\mathrm{N}-\mathrm{N}$ bond in $1(141.3 \mathrm{pm})$ compared to the corresponding value for butane-2,3dionemonoazine (2) $(136.4 \mathrm{pm})^{2}$ fits this idea quite well.

Tetrathiomethylformaldazine (4), the thio-analogue of $\mathbf{1}$, has also been subjected to a structure determination. ${ }^{9}$ It is noteworthy that this molecule, in good agreement with the ideas dealt with here, is also planar and centrosymmetric (approximately $C_{2 \mathrm{~h}}$ ).

In Table 4, structural data for the azine group are collected for compounds 1-4 and some other azines (5-8). From these data, the correlation between conformation and bond lengths mentioned previously ${ }^{2}$ is confirmed: In the planar conformation $(1,3-5,7)$ there is little $\pi / \pi$ conjugation, leading to isolated $\mathrm{C}=\mathrm{N}$ and $\mathrm{N}-\mathrm{N}$ bonds; however, in the gauche form $(2,6,8) n / \pi$ conjugation results in longer $\mathrm{C}=\mathrm{N}$ and shorter $\mathrm{N}-\mathrm{N}$ bonds. The increase in the $\mathrm{C}=\mathrm{N}-\mathrm{N}^{\prime}$ bond angle

Table 3. Experimental and calculated structure parameters of 1.(e.s.d.'s in parentheses).

\begin{tabular}{|c|c|c|}
\hline & X-Ray & MNDO \\
\hline \multicolumn{3}{|l|}{ Bond lengths/pm } \\
\hline $\begin{array}{l}N-N^{\prime} \\
N=C(1) \\
C(1)-O(1) \\
C(1)-O(2) \\
O(1)-C(2) \\
O(2)-C(3)\end{array}$ & $\begin{array}{l}141.3(4) \\
126.1(3) \\
133.9(2) \\
133.6(3) \\
143.3(3) \\
144.0(3)\end{array}$ & $\begin{array}{l}133.6 \\
131.9 \\
134.9 \\
135.5 \\
140.6 \\
140.8\end{array}$ \\
\hline \multicolumn{3}{|l|}{ Bond angles $/^{\circ}$} \\
\hline $\begin{array}{l}C(1)=N-N^{\prime} \\
O(1)-C(1)=N \\
C(2)-O(1)-C(1) \\
O(2)-C(1)=N \\
C(3)-O(2)-C(1) \\
O(2)-C(1)-O(1)\end{array}$ & $\begin{array}{l}113.0(2) \\
124.6(2) \\
119.6(2) \\
122.6(2) \\
116.1(2) \\
112.7(2)\end{array}$ & $\begin{array}{l}116.9 \\
125.3 \\
125.7 \\
120.4 \\
123.8 \\
114.3\end{array}$ \\
\hline \multicolumn{3}{|l|}{ Torsion angles $/^{\circ}$} \\
\hline $\begin{array}{l}C(1)=N-N^{\prime}=C(1)^{\prime} \\
O(1)-C(1)=N-N^{\prime} \\
C(2)-O(1)-C(1)=N \\
O(2)-C(1)=N-N^{\prime} \\
C(3)-O(2)-C(1)=N \\
C(3)-O(2)-C(1)-O(1) \\
C(2)-O(1)-C(1)-O(2)\end{array}$ & $\begin{array}{r}180.0(2) \\
-1.0(2) \\
176.7(2) \\
179.5(2) \\
0.7(2) \\
-178.9(2) \\
-3.7(2)\end{array}$ & $\begin{array}{r}180.0 \\
-1.6 \\
163.8 \\
179.2 \\
8.0 \\
-171.3 \\
-16.9\end{array}$ \\
\hline
\end{tabular}


Table 4. Important structure parameters for azines 1-8.

\begin{tabular}{lllllllll}
\hline & $\mathbf{1}^{a}$ & $\mathbf{2}^{b}$ & $\mathbf{3}^{c}$ & $\mathbf{4}^{d}$ & $\mathbf{5}^{\boldsymbol{\theta}}$ & $\mathbf{6}^{f}$ & $\mathbf{7}^{g}$ & $\mathbf{8}^{h}$ \\
\hline $\mathrm{N}-\mathrm{N}^{\prime} / \mathrm{pm}$ & 141.3 & 136.8 & 141.8 & 142.8 & 143.7 & 138.1 & 141.3 & 137.8 \\
$\mathrm{~N}=\mathrm{C} / \mathrm{pm}$ & 126.1 & 128.1 & 127.7 & 128.1 & 127.7 & 126.6 & 126.9 & 129.6 \\
$\mathrm{C}=\mathrm{N}-\mathrm{N}^{\prime} /^{\circ}$ & 113.0 & 118.0 & 111.4 & 112.2 & 110.4 & 114.5 & 112.6 & 114.8 \\
$\mathrm{C}=\mathrm{N}-\mathrm{N}=\mathrm{C}^{\prime} / /^{\circ}$ & 180.0 & 102.7 & $180.0^{i}$ & 180.0 & $180.0^{i}$ & 107.9 & 180.0 & 141.8 \\
\hline
\end{tabular}

${ }^{a}$ This paper. ${ }^{b}$ Ref. 2. ${ }^{c}$ Ref. 8. ${ }^{d}$ Ref. 9. ${ }^{\theta}$ Ref. 10. ${ }^{\prime}$ Ref. 11. ${ }^{g}$ Ref. 12. ${ }^{h}$ Ref. 13. 'Prevailing conformer; minor amount of second conformer (gauche) detected.

by a few degrees on going from the ap to the gauche conformation is in accord with these electronic interactions.

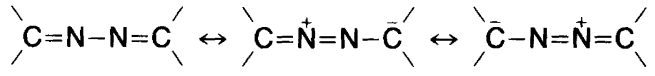

As far as the $\mathrm{C}=\mathrm{N}$ bond is concerned, compound 6 is an exception since it has a rather small value for this bond length in spite of its ac conformation. ${ }^{11}$ The variation in these structure parameters with the CNNC dihedral angle has been investigated for compound 3 by $a b$ initio calculations. ${ }^{14}$ Except for the $\mathrm{C}=\mathrm{N}$ bond lengths, which show a more complicated pattern, the results of this study are in accord with the experimental findings.

The stereoelectronic conformational model for azines described in Part $2^{2}$ considers only electronic effects. This model has successfully been applied to azines with different substituents. ${ }^{3}$ In this way, conformational properties of alkyl-substituted azines ${ }^{1}$ as well as those with acyl, ${ }^{2}$ alkoxy and thioalkoxy groups ${ }^{3}$ can be dealt with. Aromatic or other unsaturated azines like benzalazine $(7)^{12}$ and benzylidene-ketazine $(8)^{13}$ have not yet been included. The tetrabromo compound 6 still poses some problems because it is in an ac conformation ${ }^{11}$ while the analogous fluorine ${ }^{15}$ and chlorine $^{3}$ compounds are planar. We will come back to this question in a subsequent publication.

Generally, it can be stated that the conformational behaviour of aliphatic azines has been explored to a fairly high degree. All molecules investigated so far seem to confirm the introduced conformational model.

\section{Experimental}

A Perkin-Elmer 580 instrument was used to record IR spectra. The Raman spectrum of 1 was recorded on a Ramanor HG 25 (Spectra Physics Argon Laser). NMR spectra were recorded with a Varian XL-200 spectrometer using TMS as internal standard. The photoelectron spectrum of 1 was recorded on a UPG 200 from Leybold-Heraeus, with a He-I lamp $(21.21 \mathrm{eV})$ as radiation source. The MNDO calculations were performed on an IBM 4040 computer.

Azine 1 was prepared from tetrabromoformaldazine as described by Thiele, ${ }^{16}$ and recrystallized from ethyl acetate. IR $(\mathrm{KBr}): 1630(\mathrm{C}=\mathrm{N}), 1468$, 1310, 1290, $1070(\mathrm{C}-\mathrm{O}) \mathrm{cm}^{-1} .{ }^{1} \mathrm{H}$ NMR $(200$ $\left.\mathrm{MHz}, \mathrm{CDCl}_{3}\right): \delta 3.78(6 \mathrm{H}, \mathrm{s}, \mathrm{OMe}$ anti), 3.74 (6H, s, OMe syn). $\left.{ }^{13} \mathrm{C} \mathrm{NMR} \mathrm{(50.3} \mathrm{MHz,} \mathrm{CDCl}_{3}\right)$ : $\delta 154.2(\mathrm{~s}, \mathrm{C}=\mathrm{N}), 55.6\left(\mathrm{q}, \mathrm{OCH}_{3}\right.$ anti), $55.1(\mathrm{q}$, $\mathrm{OCH}_{3}$ syn).

$X$-Ray structure analysis. Crystal Data: $\mathrm{C}_{6} \mathrm{H}_{12} \mathrm{~N}_{2} \mathrm{O}_{4}, \mathrm{M}=176.17$. Monoclinic, $a=7.108$ $(1), b=6.252(1), c=9.983(2) \AA, \beta=99.12(3)^{\circ}$, $V=438.1(1) \AA^{3}$ (by least-squares refinement on diffractometer angles for 25 automatically centred reflections; $\lambda=0.71069 \AA$ ), space group $P 2_{1} / n$ (No. 14), $Z=2, D_{\mathrm{x}}=1.3357 \mathrm{~g} \mathrm{~cm}^{-3}$. White crystals. Crystal dimensions: $0.23 \times 0.19 \times 0.14 \mathrm{~mm}, \mu(\operatorname{MoK\alpha })=1.05 \mathrm{~cm}^{-1}$.

Data collection and processing: Syntex R3 fourcircle diffractometer, $\omega$ scan mode, $2 \theta_{\max }=50^{\circ}$, graphite-monochromated $\mathrm{MoK \alpha}$ radiation; 770 independent reflections measured, giving 620 with $F_{\mathrm{o}} \geq 3.5 \times \sigma\left(F_{\mathrm{o}}\right)$.

Structure analysis and refinement: The coordinates of all non-hydrogen atoms were determined 
by direct methods and refined using the SHELXTL program system ${ }^{17}$ on a NOVA $3 / 12$ (Data General) computer. The positions of the hydrogen atoms were calculated on the basis of ideal geometry and refined as rigid groups $(\mathrm{C}-\mathrm{H}$ distance $96 \mathrm{pm}, \mathrm{H}-\mathrm{C}-\mathrm{H}$ angle $109.5^{\circ}$ ). The separate temperature factors were taken as 1.2 times the $U_{i j}$ tensors for the corresponding $\mathrm{C}$ atoms. The refinements converged to $R=0.043$, $R_{\mathrm{w}}=0.045$, weighting scheme $w^{-1}=\sigma^{2}(F)+$ $4.0 \times 10^{-4} F^{2}$. Residual electron density 0.17 e $\AA^{-3}$.

Lists of calculated and observed structure factors, atomic coordinates and temperature factors of hydrogen atoms, and anisotropic temperature factors can be obtained from the Fachinformationszentrum Energie-Physik-Mathematik, D-7514 Eggenstein-Leopoldshafen 2, F.R.G., quoting reference No. 52869 together with the names of the authors and the title of the paper.

Acknowledgements. We thank Mr. W. Brett for literature searches. Financial support by the Deutsche Forschungsgemeinschaft is gratefully acknowledged.

\section{References}

1. Kirste, K., Poppek, R. and Rademacher, P. Chem. Ber. 117 (1984) 1061.

2. Korber, G., Rademacher, P. and Boese, R. J. Chem. Soc., Perkin Trans. 2 (1987) 761.

3. Korber, G. Dissertation, University of Essen, Essen 1987.
4. Dewar, M. J.S. and Thiel, W. J. Am. Chem. Soc. 99 (1977) 4899; Ibid. 4907.

5. Turner, D. W., Baker, C., Baker, A. D. and Brundle, C. R. Molecular Photoelectron Spectroscopy, Wiley Interscience, New York 1970.

6. Koopmans, T. Physica 1 (1934) 104.

7. Rademacher, P. Strukturen organischer Moleküle, VCH Verlagsges., Weinheim 1987, p. 56.

8. Hagen, K., Bondybey, V. and Hedberg, K. J. Am. Chem. Soc. 99 (1977) 1365.

9. Manotti Lanfredi, A. M., Tiripicchio, A. and Tiripicchio Camellini, M. Cryst. Struct. Commun. 4 (1975) 141.

10. Hargittai, I., Schultz, G., Naumov, V. A. and Kitaev, Y. P. Dokl. Acad. Nauk SSSR 227 (1976) 1131; Acta Chim. Acad. Sci. Hung. 90 (1976) 165.

11. Hagen, K., Bondybey, V. and Hedberg, K. J. Am. Chem. Soc. 100 (1978) 7178.

12. Burke-Laing, M. and Laing, M. Acta Crystallogr., Sect. B 32 (1976) 3216.

13. Berthou, J., Jaquier, R., Laurent, A., Marzin, C., Rerat, B., Rerat, C. and Uesu, Y. C.R. Acad. Sci., Ser. C271 (1970) 802.

14. Bock, C. W., George, P. and Trachtman, M. J. Comput. Chem. 5 (1984) 395; Skancke, A. J. Mol. Struct. 34 (1976) 291.

15. King, S. T., Overend, J., Mitsch, R. A. and Ogden, P. H. Spectrochim. Acta, Part A26 (1970) 2253.

16. Thiele, J. Liebigs Ann. Chem. 303 (1898) 69.

17. Sheldrick, G. M. SHELXTL: A Complete Program System for Solving, Refining, and Displaying Structures from Diffraction Data, Revision 4.1, Göttingen 1983.

Received January 25, 1988. 